\title{
La interrupción de las peregrinaciones etíopes a Tierra Santa en el contexto de la rivalidad entre otomanos y portugueses a principios del siglo XVI
}

\author{
The interruption of Ethiopian pilgrimages to the Holy \\ Land in the context of the rivalry between Ottomans \\ and Portuguese in the early 16 th century
}

Víctor DE LAMA DE LA CRUZ

Dpto. de Literaturas Hispánicas y Bibliografía

Universidad Complutense de Madrid

https://orcid.org/0000-0002-6497-3253

victordelama@pdi.ucm.es

\begin{abstract}
From the earliest days of Christianity, Jerusalem was the main destination for Christian pilgrimages. Those that left from the western countries are well known today due to the considerable abundance of pilgrim tales. However, for geographical, political and linguistic reasons, Ethiopian Christians carried out in the Holy Land during the Middle Ages and early modern times are little known. For this reason, an exceptional importance should be given to the story of Francisco Alvares that was spread throughout Europe about the fortune of two pilgrimages that were heading to Jerusalem from the country of Preste Juan. This story is an incomparable testimony to the political, military and religious tensions that occurred in the Red Sea environment at the beginning of the 16 th century.
\end{abstract}

Keywords: Ethiopia; Portugal; Ottoman Empire; Prester John; pilgrimages; Francisco Alvares.
Resumen: Desde los primeros tiempos del cristianismo, Jerusalén fue el principal destino de las peregrinaciones cristianas. Las que partían de los países occidentales son hoy bien conocidas debido a la considerable abundancia de relatos de peregrinos. Sin embargo, por razones geográficas, políticas y lingüísticas son poco conocidas las que realizaban a Tierra Santa los cristianos etíopes durante la Edad Media y los primeros tiempos modernos. Por eso mismo se debe conceder una importancia excepcional al relato de Francisco Álvarez que se divulgó por Europa sobre la fortuna de dos peregrinaciones que se dirigían a Jerusalén desde el país del Preste Juan. Dicho relato es un testimonio incomparable de las tensiones políticas, militares y religiosas que se produjeron en el entorno del mar Rojo a principios del siglo XVI.

Palabras clave: Etiopía; Portugal; Imperio otomano; Preste Juan; peregrinaciones; Francisco Álvarez. 
Entre las sectas cristianas que residían en Jerusalén, la etíope era una de las menos conocidas en el Occidente europeo, no solo por su idioma sino también por su aislamiento geográfico y político, Por eso, creo que resultará interesante examinar las noticias de Francisco Álvarez sobre dos peregrinaciones a Jerusalén de quienes eran considerados en Occidente los súbditos del Preste Juan. Comisionado por el rey Manuel I de Portugal, el experimentado diplomático y cronista Duarte Galvâo se hizo cargo de devolver la embajada que el rey de Portugal había recibido del negus Lebna Dengel (1496-1540)1 ${ }^{1}$ Al morir Galvâo en el mar Rojo en 1517, el nuevo embajador Rodrigo de Lima y el capellán del rey, Francisco Álvarez, se hicieron cargo de dirigir dicha embajada que llegó a Etiopía en 1520 y se prolongó hasta 1526, año de su regreso a Portugal. Con sus experiencias Francisco Alvares publicó su Verdadera Informaçam das Terras do Preste foao das Indias (Lisboa, 1540), donde describió, entre otras muchas noticias, cómo se desarrollaban las peregrinaciones a Tierra Santa hasta el momento en que Selim I sometió a los mamelucos de Egipto en 1517 y cambió completamente el mapa de Oriente Próximo. Pero antes de adentrarnos en la obra de Francisco Alvares (Álvarez en castellano) y su difusión europea, conviene contextualizar esas peregrinaciones etíopes a Tierra Santa.

\section{LAS «NACIONES DE CRISTIANOS» EN JERUSALÉN}

Desde tiempo inmemorial, Jerusalén ha sido destino de peregrinaciones judías, cristianas y musulmanas ${ }^{2}$. Una de las experiencias que más impresionaba a los cristianos occidentales que hacían su peregrinación a Jerusalén era comprobar la variedad de sectas cristianas ${ }^{3}$ que mantenían sus propios lugares de culto en la iglesia del Santo Sepulcro. En su viaje podían haber conocido peculiares ceremonias griegas en las escalas que se hacían entre Venecia y Jaffa o haber conocido a los cristianos coptos a su paso por Alejandría o El Cairo ${ }^{4}$, pero en ningún otro

1 Lebna Dengel fue conocido en Occidente como rey David. El emisario de Etiopía fue Mateus, un religioso de origen armenio. Este trajo una carta de Helena, que gobernaba durante la minoridad de su nieto David, escrita en 1509 y dirigida a don Manuel de Portugal.

2 Recordemos que los judíos acudían cada año para celebrar la Pascua, como indican las Sagradas Escrituras; y que para los musulmanes Jerusalén es la tercera ciudad santa del Islam, después de La Meca y Medina, pues desde la piedra que se custodia en la Cúpula de la Roca ascendió Mahoma al cielo a lomos de su caballo Burac.

3 El nombre de sectas cristianas es el habitual en los libros de peregrinación de la Edad Moderna, motivo por el que lo mantengo aquí.

4 Es muy interesante leer cómo Diego de Mérida nos refiere en 1511 los ritos coptos en las iglesias cristianas de El Cairo (Antonio Rodríguez MoÑIno, ed., Diego de MÉRIDA, Viaje a Oriente, en 
lugar podían apreciar las variadas formas de ser cristianos como en la iglesia del Santo Sepulcro. Aunque en este gran templo de la Cristiandad había zonas comunes por donde todos los cristianos podían pasar y detenerse a rezar, al menos desde la época de los cruzados se mantenían capillas y espacios que pertenecían privativamente, sobre todo, a los cristianos ortodoxos, a los católicos latinos y a los ortodoxos armenios. Pero también los maronitas, los jacobitas, los coptos, los etíopes, los nestorianos y los georgianos tenían sus propios espacios de culto. Los peregrinos observaban sus peculiares vestiduras sagradas y las diferencias formales de sus ritos. Se daban cuenta de que algunos clérigos acudían con su mujer e hijos, por no tener entre sus obligaciones el celibato, observaban sus atuendos o sus largas ceremonias, tomaban nota de sus largas cuaresmas, etc.

En los libros españoles de peregrinación de los siglos XVI y XVII se mencionan a menudo los lugares que ocupaba cada secta en el Santo Sepulcro. Algunos espacios fueron cambiando de dueño con el tiempo, como consecuencia de las tremendas rivalidades o del dinero con que sobornaban a los musulmanas, que desde 1517 fueron los turcos otomanos ${ }^{5}$. A la vez el peregrino observaba que llegaban en peregrinación a Jerusalén cristianos de las más variadas procedencias, occidentales y orientales. Eran muy ruidosas, por ejemplo, las peregrinaciones de los griegos ortodoxos en Semana Santa para participar en el fuego sagrado, una ceremonia que consistía en mostrar una llama, que según se decía empezaba a arder espontáneamente, con la que se iban encendiendo las velas de todos los presentes en el Santo Sepulcro.

A veces viajaban en la misma comitiva cristianos de diferente confesión o cristianos con musulmanes, como nos cuenta Diego de Mérida en su viaje al monasterio de Santa Catalina en el monte Sinaí, realizado hacia 1511. En el trayecto desde El Cairo nuestro fraile jerónimo intenta pasar por monje griego, debido a que los españoles eran peor mirados por los mamelucos tras la expulsión de los moros de Granada. De regreso a El Cairo, se suma a un grupo de mercaderes musulmanes. Anselmo Adorno y su hijo Giovanni, que procedían de Brujas, se embarcaron en Génova en 1470 desde donde cruzaron a Túnez y viajaron

Analecta Sacra Tarraconensia, 18 [1945], pp. 149-150) o la descripción de Pedro Manuel de Urrea sobre las ceremonias que acompañaban a una boda griega (Enrique GALÉ, ed., Pedro Manuel de URREA, Peregrinación de las tres casas sanctas de fherusalem, Roma y Santiago, vol. 2, Zaragoza, 2008, p. 82).

5 Por ejemplo, las pérdidas que sufrieron los latinos (es decir, los franciscanos de la Custodia) fueron en el siglo XVII muy importantes y costó mucho recuperarlas. Solo el status quo al que se llegó en 1852 garantizó una cierta estabilidad. 
a Egipto en compañía de hombres y mujeres que iban en peregrinación a La Meca $^{6}$. Era relativamente frecuente, por otro lado, que los peregrinos presenciaran el desplazamiento o los preparativos de los musulmanes en su viaje a La Meca (bajj). Es lo que sucede cuando Pedro Escobar Cabeza de Vaca llega a El Cairo en 1584 y nos brinda en su relato una minuciosa descripción de los preparativos de la caravana de camellos que iba a salir hacia $\mathrm{La} \mathrm{Meca}^{7}$. En ese momento el español está a punto de aprovechar la ocasión de sumarse a la expedición para llegar hasta el monte Sinaí ya que, por la orilla del mar Rojo, la primera parte del trayecto era común ${ }^{8}$. Igualmente comprobaremos cómo los cristianos etíopes acudían a Jerusalén también por el mar Rojo, coincidiendo en parte del trayecto con los musulmanes que iban o regresaban de La Meca.

Para una mejor comprensión de los lectores, en las guías de peregrinos más extensas se dedicaba un espacio a informar sobre las peculiares creencias y ceremonias de cada confesión cristiana. Son muchos los testimonios de peregrinos occidentales que desde el siglo XIV mencionan a los abisinios, o indianos, como generalmente se les llamaba entonces. El libro monográfico de Enrico Cerulli Etiopi in Palestina (Storia della Communità Etiopica de Gerusalemme) recoge de forma muy completa la visión occidental de este pueblo cristiano de África en su relación con Jerusalén ${ }^{9}$. En España los testimonios son más tardíos. En El viaje de la Tierra Santa (1498), traducción de la Peregrinatio in Terram Sanctam (1486), el deán de Maguncia Bernardo de Breidenbach ${ }^{10}$ dedica cierta extensión a explicar

6 Véase al respecto de Víctor de LAMA DE LA CRUZ, URBS BEATA HIERUSALEM. Los viajes a Tierra Santa en los Siglos XVI y ХVII (Catálogo de la exposición en la BNE del 22-09-2017 al 8-01-2018), Madrid, 2017, pp. 56-57.

7 Puede leerse en Pedro Escobar CabeZa de VACA, Luzero de la Tierra Sancta, Valladolid, 1587, fols. 42r-50r. Véase ahora el estudio de Víctor de LAMA DE LA CRUZ, Pedro Escobar Cabeza de Vaca en su «Lucero de la tierra Sancta», en Castilla. Estudios de Literatura, 6 (2015), pp. 367-401.

$8 \mathrm{Al}$ final Cabeza de Vaca desiste y se dirige hasta Jerusalén en una caravana de mercaderes. Viajaría después al Sinaí en la parte final de su viaje, tras regresar de nuevo a El Cairo.

9 Además, en torno a las relaciones hasta el final del imperio mameluco en 1517 pueden consultarse los trabajos de Emery Donzel, The Ethiopian Presence in ferusalem till 1527, en The Third International Conference on Bilad al-Sham (Palestine 19-24 April 1980), vol. 1, Jerusalem-Amman, 1983, pp. 93-104; Kirsten STOFFregen-Pedersen, Kirsten, The Qeddusan: The Ethiopian Christians in the Holy Land, en Anthony O'MAHONY, Göran GUNNER y Kevork HinTlian (eds.), The Christian Heritage in the Holy Land, London, 1995, pp. 129-148; y O'MAHONY, Anthony, Betweewn Islam and Christendom: the Ethiopian Community in ferusalem before 1517, en Medieval Encounters, vol. 2-2 (1996), pp. 140-154.

10 El viaje de varios nobles y religiosos alemanes fue realizado en 1483, la primera edición del libro fue publicada en latín en Maguncia en 1486 y la traducción castellana de Martínez de Ampiés en Zaragoza en 1498. 
esas diferencias de las «naciones de cristianos», así como de las creencias de los judíos y de los musulmanes. De los «abassinos» o indianos se puede leer en la versión castellana, entre otras cosas, que

en el año de 1482 envió embajada el dicho Preste Juan al papa Sixto [IV] y le prestó la obediencia demandando entonces de ser informado de nuestras costumbres que nos guardamos en los oficios divinos... Tienen gran celo de bien visitar con mucha devoción y honra los Santos Lugares [...]. Aman mucho la pobreza, pasan la vida con pocas viandas, aunque tengan muchas riquezas y bienes de fortuna. Usan vestidos hechos de lino y colorados. Tocan las cabezas hombres y mujeres de paños azules, andan con los pies descalzos, empero aunque todo lo dicho tan bien aguarden. Es mucho daño que son caídos en muchos errores. Tienen aún la circuncisión, como los moros, no entendiendo los míseros tristes aquellas palabras del apóstol Paulo: «Si os circunciéredes no habrés [sic] ayuda de Christo Jesús, ni os valdrá» [...]. Después que fueron por nos informados de la observancia nuestra romana, donde habían ellos prestado la obediencia, dijeron que luego desde adelante recibirían el santo baptismo como la iglesia romana recibe. Aún tienen otros muchos errores, que celebrando la misa consagran en pan fermentado, comulgan los niños en ambas especies, dan conformación simples sacerdotes... (Breidenbach, 1498, fols. 126r-v)

El soberbio infolio de Breidenbach conoció numerosas ediciones en el tránsito del siglo XV al XVI. También fue de los libros más reimpresos el de fray Antonio de Aranda que en el cap. XVIII de la Primera Parte de su Verdadera información de la Tierra Santa (Alcalá de Henares, 1533) dedica a los abisinios más de una página. Aranda llegó a Jerusalén a finales de 1529 y regresó a Venecia en la primavera y el verano de 1531. Como franciscano integrante de la Custodia de Tierra Santa, pasó parte de esos meses en el pequeño convento que los franciscanos tenían dentro del Santo Sepulcro, por tanto en estrecha relación con los representantes de las demás sectas. Si Francisco Alvares regresó a Lisboa hacia 1527 , las palabras de nuestro franciscano fueron escritas, solo tres o cuatro años después.

Aranda describe las creencias y costumbres de siete naciones de cristianos: los griegos, con los que existe una mayor rivalidad e inquina, los gorgios, los armenios, los jacobitas, los «abassinos», los surianos y los maronitas. De los «abassinos» dice que son los cristianos de Etiopía, que están «so el señorío del Preste Juan» (ARANDA, fols. 110v) ${ }^{11}$. Aranda nos indica que «destos ay buena copia, y están más sin miedo que otros Christianos por el miedo que han los infieles al Preste Juan, el

11 Cito en adelante por Antonio de ARANDA, Verdadera información de la Tierra Santa, Alcalá, 1563. 
cual según ellos dizen les puede hazer muy gran daño, si estos sus vasallos recibiesen algún desplazer o agravio» (ARANDA, fols. 110v-111r). En efecto, varios textos de la época manifiestan que el Preste Juan seguía siendo un rey muy respetado y temido, pues podía cambiar el curso del Nilo y desviarlo al mar Rojo, con lo que se perdería la riqueza de Egipto $^{12}$. Resulta interesante comprobar que son los etíopes quienes se sienten cerca de los latinos, quizá por las relaciones que habían establecido con Roma tras el concilio de Florencia (1441), así que son bien vistos por los franciscanos («estos se jactan de ser obedientes al papa romano y de ser conformes con nosotros; y dado que celebran en fermentato no tienen por inconveniente celebrar con nuestra ostia» (ARANDA, fol. 111r). No obstante, añade Aranda que se circuncidan y «sabatizan» coincidiendo en estas prácticas con los judíos:

Preguntándoles yo por qué se circuncidan y sabatizan; alegándoles a sant $\mathrm{Pa}-$ blo en los lugares que reprueba la circuncisión a los seguidores del evangelio, uno me mostró un libro suyo diziéndome que era el libro por donde se regían, y que en él mandaban sus mayores que se debían circuncidar, no creyendo que la circuncisión valía más por devoción que Christo se había circuncidado. Y ansí del sábado por estar tan encomendado en la ley. (ARANDA, fos. 111r)

Acostumbrado a escucharles sus rezos y cánticos en el Santo Sepulcro, los describe con cierta admiración:

Son ignorantísimos, pero digoos de verdad que en el oficio divino son diligentísimos y tan fervientes que son para confundir cuantos latinos somos. Los días principales, cuando con solemnidad celebran, cierto parecen en la psalmodia que está presente Dauid; y en la misa, que la dicen alguno de los apóstoles, usan por instrumentos para cantar la psalmodia, la cual cantan todas las noches de las grandes solemnidades de atambor y sonajas; y cantan a versos en coro, como cuando allá en nuestra tierra hacen las labradoras fiesta y saltan a modo de baile estándose en un lugar ${ }^{13}$; y esto con tanto fervor y tan fijados los ojos en el cielo, que a la verdad nos hacen entender qué cosa sea júbilo, porque vemos a la clara que exultando jubilan, y jubilando exultan. (ARANDA, fol. 111rv)

12 Es lo que afirma, por ejemplo, Diego de Mérida a principios del siglo XVI (Antonio RoDRíGUEZ MoÑINO, ed. Viaje a Oriente, 1945, pp. 45-46). Son abundantes los testimonios de peregrinos de los siglos XIV y XV que regresaban a Occidente creyendo que el Preste Juan podía dejar sin agua a los egipcios. Nadie llegó tan lejos como el portugués Alfonso de Alburquerque que hacia 1513 escribió a su rey, Manuel I, pidiéndole obreros que trabajaban en las levadas de Madeira para que se trasladasen a Etiopía a desviar las aguas del Nilo.

13 Sobre la danza sagrada de los etíopes, que llamaba la atención de los peregrinos occidentales en Jerusalén, véase Enrico CERUlli, Etiopi in Palestina. Storia della Communità Etiópica de Gerusalem$m e, 2$ vol. 1, Roma, 1943, pp. 244 y ss. 
Destaca nuestro franciscano la pobreza de su indumentaria y su abstinencia, sus peculiares danzas y, en lo referente al idioma, el uso como los latinos de una lengua que casi nadie de ellos la entiende:

Dizen estos abasinos o indianos el oficio en su propia lengua y sus propios caracteres, esto es, en indiano y no caldeo. Como allá en España algunos creíamos, verdad es que en lo que toca a la escriptura sacra del testamento viejo, dado que con caracteres indianos está escripto, tiene empero gran similitud con el caldeo ${ }^{14}$ en las palabras, y así no todos entienden lo que leen, según acaesce a los que leen nuestro latín; y no saben gramática. (ARANDA, fol. 112r)

Aranda observa la extrema devoción de estos cristianos al celebrar la liturgia, pero también su primitivismo e ignorancia; los ve cercanos a Roma y son los mejor tratados en el recuento de sectas, pero no entra en detalles teológicos, los del monofisismo, por ejemplo, que también los separaba de los católicos.

\section{LAS DIFICULTADES DEL CRISTIANISMO ETÍOPE}

Hasta aquí estas rápidas pinceladas sobre los etíopes que residían en Jerusalén vistos por el deán de Maguncia y por fray Antonio de Aranda. Conviene ahora dedicar unas líneas a conocer el contexto político y religioso en que se desarrolló el cristianismo abisinio. Los primeros periodos de la historia de Etiopía se explican teniendo en cuenta su situación estratégica. Las relaciones de los países costeros del mar Rojo, como era el reino etíope de Aksum (siglos I-VII d.C.), con los imperios de la Antigüedad clásica, el imperio romano y el persa, se explican por sus rivalidades para conseguir el dominio del comercio con la India. La ruta de Alejandría, el delta del Nilo y el mar Rojo fue dominada por el imperio romano y después por el imperio bizantino, en tanto que la ruta interior de Siria, que cruzaba Siria y Mesopotamia, era controlada por los persas. Está claro que la situación estratégica de Etiopía, a la entrada del mar Rojo, le dio cierta importancia como escala obligada hacia el Mediterráneo tanto de las mercancías indias como de las del este africano, transportadas unas y otras al compás de los vientos monzones. Los investigadores vienen admitiendo que el cristianismo se introdujo en el reino

14 Está claro que Antonio de Aranda utiliza el término caldeo para referirse a la lengua litúrgica de la lengua ortodoxa etíope, es decir, al ge'ez, lengua que sigue siendo la oficial de la iglesia etíope y fue en Etiopía la lengua administrativa y legal hasta mediados del siglo XIX. De ahí el paralelismo que menciona Aranda con el uso del latín por parte de la iglesia de Roma. 
de Aksum, según el relato de Rufino de Aquilea (345-411) y otras fuentes que lo confirman, cuando los hermanos Frumencio y Edesio, salvándose de una masacre en un puerto del mar Rojo, llegaron a Etiopía y convirtieron al cristianismo al rey Ezana a principios del siglo IV, aunque hay quien defiende una introducción más temprana ${ }^{15}$. Fue en esta época de Ezana cuando se difundió la escritura ge'ez, que sustituyó al griego en la liturgia y que todavía sigue utilizándose. Tras la conversión de Ezana, Frumencio fue enviado por el monarca a solicitar del patriarca copto de Alejandría, San Atanasio, que nombrara un obispo para Etiopía. Atanasio eligió al propio Frumencio, quien se convirtió así en el primer obispo de Etiopía. Nació esta variedad del cristianismo, por tanto, vinculada a la iglesia copta de Alejandría y de dicho patriarcado ha dependido formalmente hasta mediados del siglo XX.

La expansión del califato omeya en el siglo VII, y luego del fatimí en el X, dejó aislado al reino de Aksum en el nordeste de África. Se quebró así cualquier expectativa de influencia etíope hacia el norte en la cuenca del Nilo (Nubia y Meroe) y del comercio marítimo en el mar Rojo, al tener que replegarse hacia el interior de África. En consecuencia el cristianismo etíope resultó aislado, salvo el débil cordón umbilical que le unía a los coptos egipcios, una variedad cristiana que sobrevivió con dificultades en un país dominado por los musulmanes. La principal consecuencia de estos hechos fue el advenimiento de la dinastía Zagüe (1137-1270) y el traslado de la capital de Aksum, ciudad que se encontraba en el norte, hasta Roha, que desde entonces empieza a llamarse Lalibela, por el nombre del monarca Gebre Mesqel Lalibela. En esta época se tallaron las famosas iglesias monolíticas etíopes de la región de Lalibela. También fue durante el gobierno de esta dinastía cuando los cristianos etíopes consiguieron una capilla en el Santo Sepulcro, gracias a la tolerancia religiosa de Saladino tras reconquistar Jerusalén a los Cruzados en $1187^{16}$. A lo largo del siglo XIII, pero sobre todo en

15 En una religión que presume de su antigüedad, se ha vinculado la fundación de la Iglesia etíope con Felipe el Evangelista (Hechos de los Apóstoles, 8), el cual habría convertido al cristianismo al tesorero del rey de Etiopía, cuando el etíope regresaba de una peregrinación a Jerusalén. Otra tradición defiende que el cristianismo se introdujo en Etiopía justo después de Pentecostés. Juan Crisóstomo menciona que los etíopes de Jerusalén eran capaces de entender la predicación de San Pedro. E incluso se admite una posible evangelización de Etiopía por parte del apóstol Mateo. Como dichas teorías son muy difíciles de demostrar, modernas revisiones del período histórico del rey Ezana ponen el énfasis en formas religiosas tradicionales que coincidieron con el triunfo del cristianismo en un momento de prosperidad política, como demuestra Steven KaPLAN, Ezana's Conversión Reconsidered, en fournal of Religion in Africa, 13-2 (1982), pp. 101-109.

16 Sobre los cristianos etíopes en Jerusalén en tiempos del Reino Latino, véase Emery van DoNZEL, Were there Ethiopians in Ferusalem at the time of Saladin's Conquest in 1187?, en Krijna Nelly 
el XIV, se empezó a sospechar que el reino del Preste Juan podía encontrarse en una de las tres Indias, la que se encontraba en el Cuerno de África. La dinastía Zagüe quedó derrocada en 1270 por Yekuno Amlak, que afirmó ser descendiente de la antigua familia real de Aksum. Según decían, esta saga se remontaba hasta Menelik I, el hijo que había nacido de los amores del rey Salomón con la reina de Saba, motivo por el cual se la denominó monarquía salomónica ${ }^{17}$.

El siglo XV significó para Etiopía el establecimiento de contactos diplomáticos con Occidente. Esa apertura se debió sobre todo al negus Zar'a Yaqob, el emperador más influyente en la historia de la iglesia de Etiopía, quien tuvo que abordar la división religiosa que implicaba la observancia bíblica del sábado, muy arraigada en la secta de Ewostatewos (1273-1352), frente a los obispos coptos defensores de guardar el descanso del domingo, así como la cuestión de la circuncisión que el emperador no llegó a desarraigar. Zar'a Yaqob fue además un notable escritor, que expresó sus ideas sobre la religión y las reformas eclesiásticas en su libro Mabsafa Berba («El Libro de la Luz») y en otros libros ${ }^{18}$.

Hubo intercambios de embajadas entre Yeshaq I, el antecesor de Zar'a Yaqob, y el rey de Aragón Alfonso el Magnánimo ${ }^{19}$. Pero el más célebre de estos encuentros se produjo cuando en 1441 Zar'a Yaqob hizo llegar a cuatro emisarios etíopes al concilio de Florencia ${ }^{20}$, que se había reunido para la reforma

CiggaAR y Herman G.B. Teule (eds.), East and West in the Crusader States II, Leuven, 1999; y también Cates BALDRIDGe, Prisoners of Prester Fohn: The Portuguese Mission to Ethiopia in Search of the Mytical King, 1520-1526, Jefferson (North Carolina), 2012.

17 Taddesse TAMraT, Church and state in Ethiopia, 1270-1527, Oxford, 1972.

18 Además de la traducción italiana (Il libro della luce del Negus Zar'a Yā'qob (Mașhafa Berhān), Louvain, 1964), contamos con la traducción inglesa de Mașhafa Berhān realizada por Ephraim IsAaC, A New Text-Critical Introduction to «Mașhafa Berhān», Leiden, 1973. (1973). Otros dos libros suyos fueron Mabsafa Milad («El Libro de la Natividad») y Mabsafa Selassie («El Libro de la Trinidad»), de contenido teológico.

19 En 1428 Alfonso V recibió una carta de dos embajadores de Yeshaq I de Etiopía, en la cual le proponía una alianza contra los musulmanes, afianzada esta por un doble matrimonio; uno de ellos sería el del infante Don Pedro con la hija de Yeshaq, a condición de que éste llevara a Etiopía a un grupo de artesanos. No se sabe si Alfonso respondió a esta carta, pero sí hay constancia de un mensaje enviado por el Magnánimo a Zara Yaqob en 1450, el sucesor de Yeshaq, al que le decía que estaría encantado de enviarlos si se garantizaba su seguridad, ya que en una ocasión anterior toda una expedición de trece de sus súbditos habían perecido en el viaje. (Giron BESHAH y Morid Wolde AREGAY, The Question of the Union of the Churches in Luso-Ethiopian Relations [1500-1632], Lisboa, 1964, pp. 13-14). Para las relaciones de Alfonso V con Etiopía, véase Constantin MARINESCU, La politique orientale d'Alfonse V d'Aragon, roy de Naples (1416-1458), Barcelona, 1994, pp. 13-28.

20 Enrico Cerulli, Eugenio IV e gli Etiopi al Concilio di Firenze nel 1441, Roma, 1933. Dicho concilio se había iniciado en Basilea en 1431, se trasladó a Ferrara en 1538 y al año siguiente a Florencia donde terminó en 1445. Sobre dicho concilio y las relaciones entre Europa y Etiopía, véase ahora 
de la iglesia de Occidente, pero que tenía por objeto principal la unión de las Iglesias Orientales con Roma. Allí pudieron los etíopes entrevistarse con Eugenio IV y, mediante la bula Cantate Domino (Sesión XI, firmada el 4 de febrero de 1442), se clarificó el canon de las Escrituras, una de las diferencias que se pretendía corregir ${ }^{21}$. De poco sirvió que los emisarios etíopes repitieran que en su reino ningún monarca había llevado el nombre de Preste Juan, porque los europeos siguieron pensando que Etiopía era el país de este rey fabuloso. Es de reseñar la obstaculización de estos contactos por parte de los coptos de Alejandría, los cuales no veían bien que los etíopes negociaran directamente con Roma ${ }^{22}$.

No mucho después las relaciones entre Roma y el cristianismo etíope entraron en una nueva fase. En 1450 una embajada del emperador Zar'a Yaqob compuesta de un religioso etíope, de un siciliano, que se estableció luego en Etiopía, y de «un moro» llegó a Roma para tratar de asuntos importantes con la Santa $\mathrm{Sede}^{23}$. Parece que en ese encuentro no se produjeron grandes avances, pero unos años más tarde el papa valenciano Calisto III (1455-1458) intentó comprometer al negus en las operaciones contra los turcos. Se conservan las cartas que intercambiaron el Papa y Alfonso V de Aragón con los etíopes, quienes expresaron el deseo de mantener la unión de las iglesias ${ }^{24}$.

No cabe ninguna duda de que los etíopes peregrinaron con asiduidad a Jerusalén al menos desde la época de las Cruzadas. La capilla que poseían en el Santo Sepulcro así lo revela, pero hay numerosos datos concretos que aportan los historiadores ${ }^{25}$. Uno bien conocido es el encuentro en Jerusalén entre un embajador etíope, enviado por el emperador Eskender, y el franciscano alemán Paul

el trabajo de Marta KozLOwska First Contacts between Ethiopia and Europe (from de Fourteenth until Beginning of the Sixteenth Century), en Studies of the Department of African Languages and Cultures, vol. 37, 2006, pp. 5-46.

21 Samantha KelLY, Ewostateans at the Council of Florence (1441): Diplomatic Implications between Ethiopia, Europe, Ferusalem and Cairo, en Afriques 2016. Afortunadamente se han salvado los documentos y la correspondencia relacionada con dicha embajada etíope, incluso los textos en ge'ez traducidos al latín y al italiano, reunidos por Georg HofMANn, Epistolae pontificiae ad concilium Florentinum spectantes, vol. 2, Rome, 1944.

22 Alberto ElLI, Storia de la Chiesa Ortodossa Tawahedo d'Etiopia, 2 vols., Milano, 2017, pp. 415-445.

23 «pro nonnulis arduis etiam negotiis etiam honorem sancte apostolice sedis concernentibus» (Jean RICHARD,

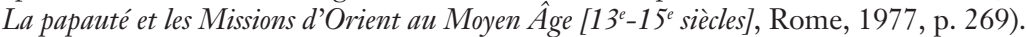

24 Francesco CERONE, La politica orientale di Alfonso di Aragona, Napoli, 1903.

25 Enrico Ceruli, Etiopi in Palestina [ver n. 13]; Matteo SAlvadore, The African Prester fohn and the Birth of Ethiopian-European Relations, 1402-1555, London-New York, 2017; Alberto ELLI, Storia de la Chiesa Ortodossa Tawahedo d'Etiopia, 2 vols., Milano, 2017. 
Walther von Guglingen. Cuenta Paul Walther en su Itinerarium Terrae Sanctae que este embajador etíope se dirigía a Constantinopla con la finalidad de que la iglesia ortodoxa enviase a Etiopía un obispo. El alemán le convenció para que hablase antes con fray Giovanni Tomacelli, el custodio de Tierra Santa entre 1478 y 1481, que al enterarse del propósito del embajador le dijo: «Señor, señor, por qué quieres que tu rey sea coronado por los griegos, que no son católicos, sino heréticos y cismáticos excomulgados por la verdadera iglesia?» Tomacelli le hizo la siguiente propuesta: «Cruza el mar y dirígete a Roma: allí encontrarás al Papa, el verdadero representante de Cristo, la cabeza de la Iglesia Universal y el jefe religioso de todos los cristianos ${ }^{26}$. El embajador alegó que Roma estaba muy lejos y que estaría encantado de poder recibir a un enviado de hombre tan poderoso, pero que él podría esperar solo cinco meses en El Cairo, sin posibilidad de retrasar más su regreso.

No obstante, en la primavera de 1481 Giovanni Battista Brochi da Imola acompañó al embajador etíope de Jerusalén a Roma, donde se entrevistó con Sixto IV (Papa entre 1471 y 1484) y acordaron enviar la embajada de un obispo católico a la tierra del Preste Juan para que conociera sus creencias y ritos, todo ello con vistas a establecer relaciones entre ambas iglesias ${ }^{27}$. Cabe pensar que los etíopes acudían a Roma no solo para reconocer la supremacía del Papa, aceptando que este enviase un obispo a la Iglesia de Etiopía, sino también para encontrar aliados frente a los mamelucos. De hecho parece que de Roma partieron dos obispos y uno de ellos, Juan de Calabria, llegó a Etiopía donde encontró cierto número de italianos que se habían establecido, voluntariamente o a la fuerza, en las tierras del Preste Juan. Entretanto, Sixto IV había concedido a los monjes abisinios una capilla en Roma, con lo que la unión con la iglesia etíope, por muy vaga que fuese, se veía como efectiva ${ }^{28}$. Ese fue el origen del establecimiento definitivo del cristianismo etíope en Roma, en concreto en la iglesia de Santo Stefano degli Abisini $^{29}$.

Con el nuevo siglo se iban a articular unos nuevos conflictos y unas nuevas alianzas políticas en la zona. El descubrimiento por parte de los portugueses de la nueva ruta hacia la India alteró sus relaciones con los mamelucos primero, y con los otomanos después, propiciando unas alianzas entre Portugal y Etiopía que serían determinantes en las peregrinaciones etíopes de estos últimos.

26 Matteo Salvadore, The African Prester Fobn [ver n. 25], p. 67.

27 Matteo Salvadore, The African Prester Fohn [ver n. 25], pp. 67-68.

28 Jean RICHARD [ver n. 23], p. 269.

29 Matteo SAlvadore, The African Prester Fobn [ver n. 25], p. 71. 


\section{LA DENODADA BÚSQUEDA DEL PRESTE JUAN POR PARTE DE LOS PORTUGUESES}

A pesar de estos tímidos contactos, el cristianismo etíope apenas era conocido en Europa por la presencia de algunos religiosos en Roma y en Jerusalén. Muy diferente fue la actitud de Portugal, especialmente la de Enrique de Portugal (llamado «el Navegante» desde el siglo XIX) a quien debieron los portugueses el primer empeño serio en dar con el paradero del Preste Juan a mediados del siglo XV. Quizá por eso, y por los intereses comerciales y militares que auspiciaba el feliz encuentro, fueron los monarcas portugueses a finales del siglo XV y en el XVI quienes más energías invirtieron en su localización.

Tras la muerte en 1460 del Navegante, Juan II de Portugal envió a Fray Antonio de Lisboa y a Juan de Monterrogo para buscar el reino del Preste Juan en 1486. No conforme con el fracaso de esta expedición por no dominar la lengua arábiga, el monarca portugués envió en 1487 a Pedro de Covilha y a Alonso de Paiva a la India para transmitir a rey tan fabuloso un mensaje de amistad, viaje que termina con una carta de Covilha manifestando que no se encuentra rastro de Preste en la India y que el único rey sacerdote debía de ser el negus de Etiopía ${ }^{30}$. Después de azarosos viajes, Covilha fue retenido en Etiopía por Naod, emperador entre 1498-1508, quien le colmó de riquezas. Allí alcanzó la categoría de consejero real y en 1508 pasó a servir a la nueva reina Helena, quien por su mediación envió al embajador Mateus de Etiopía para entrevistarse con el rey de Portugal, que desde 1495 era Manuel I. Este rey quiso que en 1515, de vuelta a Etiopía, acompañara a Mateus una embajada que, por diversas complicaciones, no llegó a su destino hasta 1520 y que se prolongó hasta 1526. Uno de los frailes era Francisco Álvarez, capellán del rey, quien resultó de singular importancia para el conocimiento del reino del Preste Juan en Occidente, a quien Covilha confió la información acumulada y le transmitió sus vivencias de más de treinta años cuando coincidieron en Etiopía ${ }^{31}$.

30 Ese año el rey Juan II de Portugal financiaba el gran viaje de Bartolomé Dias que se proponía circunnavegar el continente africano. Entre los encargos de Juan II se contemplaba la localización del reino del Preste Juan y entablar relaciones con él. Aunque dobló el cabo que llamó de las Tormentas (luego rebautizado por Juan II como cabo de Buena Esperanza), no pudo remontar toda la costa Oriental de África debido a que su tripulación, con escasas provisiones y las naves maltrechas, le obligó a regresar a Portugal. Explica este encargo João de Barros en Asia. Dos feitos que os Portugueses fizeram no descobrimento e conquista dos mares e terras do Oriente. Primeira década (Lisboa, 1552).

31 Mucho después del regreso a Lisboa, en 1532, Alvares llevó al papa la carta por la que emperador Lebna Dengel le renovaba su obediencia. Dicha carta se la entregó a Clemente VII en Bolonia 1533 y está recogida por Ramusio en su primer volumen de Navigationi et viaggi (1550). 
Hubo que esperar hasta 1540 para ver publicada la obra de Francisco Alvares derivada de esa embajada y de su encuentro con Covilha. Su título completo era Verdadera Informaçam das Terras do Preste Foao das Indias, segundo vio e escreveo ho padre Francisco Alvares Capellã del Rey Nosso Senhor (Lisboa, Luis Rodrigues, $1540)^{32}$ y fue la primera obra dedicada por extenso a describir cómo era el reino donde presumiblemente reinaba el Preste Juan ${ }^{33}$. Luego, una versión parcial de la obra se recogió, en italiano, en el Primo volumen delle navigationi et viaggi de G.B. Ramusio (Venecia, 1550) y poco después apareció la traducción española, Historia de las cosas de Etiopía (Amberes, Juan Steelsio, 1557), a cargo de fray Tomás de Padilla. La obra debió de resultar particularmente interesante a los lectores portugueses, italianos y españoles del siglo XVI, pues a través de ella tuvieron noticias fiables de un país desconocido, que despertaba una altísima curiosidad entre las personas cultivadas, y pudieron apreciar hasta qué punto eran peculiares sus creencias religiosas. La obra de Ramusio se reeditó pronto. Del éxito español de la obra de Alvares nos habla una reedición en Zaragoza (Agustín Millán, 1561) y una nueva traducción publicada en Toledo (Pedro Rodríguez, 1588), a cargo en este caso de Miguel de Selves ${ }^{34}$. Pronto fue publicada también en francés (Amberes, 1558, y París, 1674) y en alemán (Eisleben, 1566) ${ }^{35}$.

32 El título parece inspirado en el que poco antes fray Antonio de ARANDA había puesto al relato de su viaje y guía de Tierra Santa: Verdadera información de la Tierra Santa (Alcalá de Henares, 1533).

33 La obra de Alvares fue la primera que, de forma fehaciente, desmintió la creencia de que el reino de Etiopía fuera el de un personaje fabuloso lleno de riquezas, ya que Etiopía era entonces un reino aislado, sin armada y acosado a menudo por los reinos vecinos. En este momento histórico su Emperador soñaba con una alianza con los portugueses para que les defendieran de los turcos y otros vecinos.

34 Su título también fue diferente: De las cosas de Ethiopía en la qual se cuenta muy copiosamente, el estado y potencia del Emperador della (que el que muchos han pensado ser el Preste Iuan) con otras infinitas particularidades assí de la religion de aquella gente, como de sus ceremonias, según que de todo ello fue testigo de vista Francisco Aluarez, capellán del Rey don Manuel de Portugal, traducida por Miguel de Selues.

35 No es momento de detenernos en describir la accidentada historia textual de la obra de Francisco Alvares. Como se apuntó más arriba, Ramusio no publicó entera la versión portuguesa de 1540, pues declara tomar una parte de ella y otra de un manuscrito de la Biblioteca Marciana de Venecia, hoy perdido. Pero es que ni siquiera la prínceps, según Roberto Almagià, recoge la redacción completa de Alvares, pues según este investigador, el portugués compuso una obra dividida en cinco libros: el primero dedicado a una explicación general del país, sus límites territoriales, fenómenos astronómicos con significación cosmográfico y sobre las fuentes del Nilo; el segundo sobre la fertilidad del suelo y sus recursos vegetales y minerales; el tercero sobre los animales terrestres y las aves, y especialmente sus animales salvajes como los elefantes; el cuarto sobre costumbres, literatura, la enseñanza, la corte y las ceremonias, su monarca, el ejército, instituciones y leyes; y el quinto sobre la religión, sus iglesias, ritos de matrimonio y defunción, la vida de sus abundantes monjes, etc. El profesor Almagià postula dicha reconstrucción contando con otros tres manuscritos descubiertos por él en las Bibliotecas Vaticanas (Roberto Almagià, Contributi alla storia della conoscenza dell'Etiopia, Padova, 1941). 
Cuando se publica en 1557 la obra en castellano, nos encontramos en el momento histórico en que Carlos $V$ ya había renunciado a seguir siendo rey de España al abdicar en favor de su hijo Felipe II y en ese año llega a su retiro de Yuste. El idioma español había alcanzado en Europa su prestigio más alto. La traducción de estas obras portuguesas de contenido geográfico y religioso al castellano suponía en el siglo XVI dar a conocer a un mundo mucho amplio todo aquello que los descubridores portugueses iban conociendo en sus viajes de navegación. Las motivaciones religiosas quedan expresadas por el impresor antuerpiense Juan Steelsio ${ }^{36}$ cuando le propuso a Tomás de Padilla publicar su traducción. Este manifiesta en la dedicatoria a don Antonio de Zúñiga, que

me lo rogó demasiadamente [Juan Steelsio], diciendo que además del servicio que se hacía a Dios en ello, movería también los corazones de muchos, a que particularmente le orasen y suplicasen, que por su infinita piedad y misericordia, juntase en verdadera conformidad la iglesia de Etiopía con la de Roma ${ }^{37}$.

Quizá convenga recordar que la iglesia etíope se remonta al menos a las discusiones teológicas del siglo IV. Como los armenios y los coptos de Alejandría, los etíopes eran monofisitas, es decir, defendían la unión o la fusión entre la naturaleza divina y humana y no como única naturaleza divina. Por otro lado,

36 Cito en adelante por esta edición castellana: Francisco Álvarez, Historia de las cosas de Etiopía, Amberes, 1557. Steelsio fue uno de los más activos impresores de obras castellanas en el Amberes del Emperador. Había publicado ya en 1543 los exitosos Evangelios y Epístolas que por todo el año se leen en la Yglesia, comentados por Ambrosio de Montesino. Y de su taller salieron obras religiosas de Azpilcueta, fray Luis de Granada o Constantino Ponce de la Fuente (Jaime MoLL, Amberes y el mundo hispánico del libro, en Werner THOMAS y Robert A. VERDONK [eds.], Encuentros en Flandes: relaciones e intercambios hispanoflamencos a inicios de la Edad Moderna, Leuven, 2000, pp. 117-131).

37 Pero la pujanza y extensión de la lengua castellana era una razón de mucho peso que fray Tomás de Padilla deseaba destacar: «Persuadíame también a ello ver que esta relación no se hallase sino en la lengua portuguesa, la cual por ser algo cerrada y áspera no es tan conversable fuera de sus reinos, cuanto hoy en día vemos ser la castellana no solo en toda España, más en Italia, Hungría, Alemania y en especial en estos estados de Flandes, donde pocos caballeros y mercaderes se hallan que no procuren muy bien hablar; pues en Francia, Inglaterra y Berbería, de creer es que hay muchos que se precian de sabella. Sin estos reinos de Europa y África, es manifiesto que en las Indias de Castilla, quarta parte del mundo, son infinitas poblaciones por los reinos de la Nueva España, Nueva Galicia, Castilla del oro, Nicaragua, Popayán, Perú, Chile, Río de la Plata, Nueva Andalucía, Nueva Granada, provincias de Cumaná, Venezuela, Santa Marta, Santa Marta, Cartagena, Tierra firme y en muchas islas y grandes como la de San Juan, Española, Cuba, Jamaica, en todos los cuales reinos y provincias, que se extienden por más de dos mil leguas de norte a sur, no se trata en otro lenguaje, ni obedescen otras leyes que las de Castilla». 


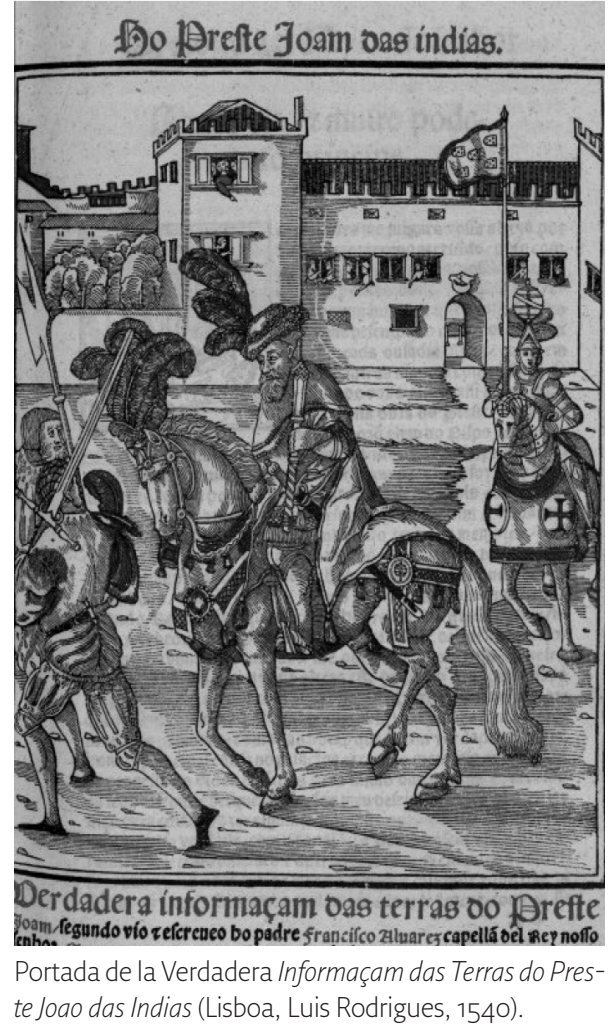

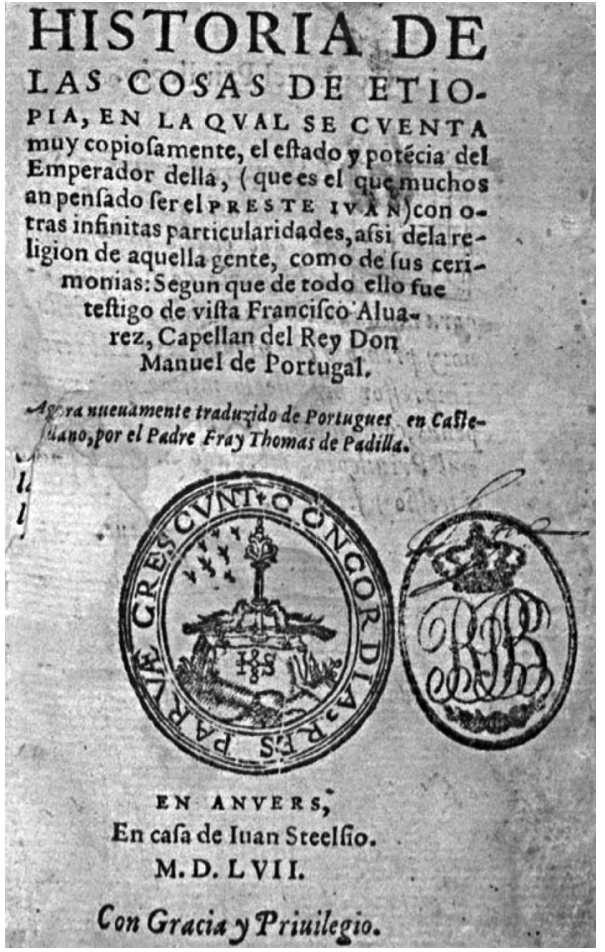

Portada de la Historia de las cosas de Etiopía (Anvers, Juan Steelsio, 1557).

conservaban diferencias notables con la iglesia de Roma: se permitía la poligamia si el hombre podía mantener a varias mujeres ${ }^{38}$, los matrimonios se disolvían con facilidad $^{39}$, las bodas se celebraban con ritos semejantes a los de los griegos ${ }^{40}$, no existía el celibato ${ }^{41}$, mantenían la circuncisión que se realizaba en privado ${ }^{42}$,

38 «Un hombre que se decía Ababitay tenía tres mujeres y aun se decía que había tenido siete y que d'ellas había habido treinta hijos» (Francisco Álvarez, Historia [ver n. 36], fol. 25v).

39 «os casamientos no son firmes acá, porque por cualquier cosa se apartan» (Francisco ÁLVAREZ [ver n. 36], fol. 25v).

40 Francisco ÁlvareZ [ver n. 36], fols. 25v-26r.

$41 \ll$ Si algunos guardan la perfección del matrimonio son los clérigos que no se pueden apartar de sus mujeres y los labradores que guardan amor a las suyas, porque les ayudan a criar sus hijos, y a limpiar y aderezar sus labranzas» (Francisco ÁLVAREZ [ver n. 36], fol. 26v).

42 «Esto cada uno lo hace sin alguna ceremonia, porque dicen que así lo hallan escrito en los libros donde Dios mandó que se circuncidasen» (Francisco ÁlvarEZ [ver n. 36], fol. 27r). 
costumbre que se había extendido a las mujeres ${ }^{43}$. El bautismo se retrasaba en los niños hasta los cuarenta días de haber nacido y en las niñas a los sesenta. Por otro lado, entran descalzos en las iglesias como los coptos egipcios, tienen cincuenta días de cuaresma, el bautismo y los entierros se celebran con rituales muy distintos de los que conocían los portugueses ${ }^{44}$, etc. Conservaban los textos sagrados en ge'ez, la lengua litúrgica de la Iglesia ortodoxa etíope, que no coincidían en muchos aspectos con el cristianismo copto de Alejandría, patriarcado del que dependió hasta 1959. Por lo general el cristianismo etíope mantiene algunas tradiciones apegadas al Viejo Testamento, como el reconocimiento de la reina de Saba y sus amores con Salomón, origen reivindicado por la monarquía salomónica; lo mismo cabe afirmar de algunas vinculaciones con el judaísmo como la circuncisión o el descanso del sábado, tradiciones nada extrañas en una comunidad religiosa aislada desde los primeros siglos del cristianismo.

\section{EL RELATO DE FRANCISCO ÁLVAREZ Y LA INTERRUPCIÓN DE LAS PEREGRINACIONES EN SU CONTEXTO GEOESTRATÉGICO}

Cuando Vasco de Gama llegó a Calicut ${ }^{45}$ en mayo de 1498, reveló sus intenciones con claridad: «Vimos buscar cristãos e especiaria». Desde ese momento se supo en aquellas latitudes que había llegado a la India un competidor de los musulmanes en el comercio de las especias. Por otro lado, obsesionados en encontrar el reino del Preste Juan, y sabedores de que los musulmanes no tenían imágenes, durante un tiempo los portugueses creyeron que las tallas de los dioses hindúes eran cristianos.

Desde el comienzo del nuevo siglo, los roces y enfrentamientos entre musulmanes y portugueses fueron en aumento en el mar arábigo. De poco sirvieron las quejas y amenazas que el soldán Kansu al Ghuri, que acababa de llegar al poder en 1501, dirigió al Pontífice, a Manuel I de Portugal y a Fernando el Católico. Así que una de las principales preocupaciones de $\mathrm{Al}$ Ghuri fue construir una flota que frenara el poder portugués en el Océano Índico y mantener el monopolio del

43 «También se circuncidan las mujeres, como los hombres, que es cosa de notar, y esto en la ley del testamento viejo nunca lo guardó» (Francisco ÁlvAREZ [ver n. 36], fol. 27r).

44 Francisco ÁlVAREZ [ver n. 36], fol. 28r.

45 Hoy es Kozhicode, ciudad del estado de Kerala, al suroeste de la India, conocida como la «ciudad de las especias». No debe confundirse Calicut con Calcuta, ciudad que se encuentra al este de la India en el golfo de Bengala. 
comercio de las especias. Hasta 1508 tuvieron que esperar los mamelucos para lograr la importante victoria naval de Chaul (al sur de Bombay) sobre Lorenzo de Almeida. Esta derrota no quedó impune, pues la flota portuguesa, comandada por su padre Francisco de Almeida, se vengó de mamelucos y otomanos en 1509 infligiéndoles la derrota naval de Diu (una pequeña isla junto a la costa en el norte de la India) que consagró la hegemonía de los portugueses en el Índico y les permitió moverse con plena libertad en esas aguas.

La paz entre el imperio otomano y Egipto se había mantenido durante el mandato de Bayaceto II. Los hechos se precipitaron cuando su hijo Selim I, que no soportaba los hostigamientos y avances por el este de la nueva dinastía safávida persa, lo destronó en 1512. Después de derrotar al ejército persa en la llanura de Chaldirán (1514), Selim se dirigió al sur contra los mamelucos, a quienes venció en la batalla de Marj Dabiq el 24 de agosto de 1516 al norte de Alepo donde perdió la vida $\mathrm{Al}$ Ghuri.

La fecha de 1517 marca el fin de una época en la historia de Etiopía. No es casualidad que coincida con el fin del imperio mameluco, cuando Selim I, tras arrebatarles los territorios de Siria y Palestina, entró en El Cairo el 23 de enero de 1517 e hizo colgar en la puerta de Bab Zuwaila a los miembros del gobierno de Tuman Bey, el nuevo sultán que no había aceptado someterse a su poder ${ }^{46}$. Junto con Egipto, el resto de los dominios mamelucos, incluyendo las ciudades santas de La Meca y Medina, pasó a depender de la Sublime Puerta.

La rivalidad entre los mamelucos y los portugueses en el mar no había afectado a las relaciones cordiales entre Egipto y Etiopía, de manera que las peregrinaciones etíopes a Tierra Santa pudieron desarrollarse libremente en el territorio egipcio y el mar Rojo. Pero justo en esa segunda década del siglo XVI los portugueses consiguieron tener noticias ciertas del negus de Etiopía, el deseado Preste Juan, a quien los portugueses llevaban buscando casi cien años. El contacto definitivo se produciría a través de su embajador Mateo, que había logrado en 1512 entrevistarse en Goa con Alfonso de Albuquerque y luego en 1513 con el rey Manuel I en Lisboa. Cuando Selim I sometió al imperio mameluco y se apoderó de todos sus dominios, su diplomacia ya tenía conocimiento de los intentos portugueses de establecer relaciones con el reino del Preste Juan, cuya ayuda consideraban primordial para apoyar su expansión por Oriente.

46 Bab Zuwaila es la principal puerta orientada al sur en El Cairo fatimí. No era la primera vez que dicha puerta había servido para un escarnecimiento público. En 1260 el general Mongol Hulagu, tras la caída de Damasco, envió a seis emisarios a El Cairo ante el sultán Qutuz para que se entregara. Qutuz, ofendido, mandó cortar por la mitad a los enviados de Hulagu y mostró sus cabezas en Bab Zuwaila. 
Llegados a este punto, debemos volver al texto de Francisco Alvares dedicado a la peregrinación. Aparece en la obra después de describir el fabuloso tesoro del Emperador guardado en cuevas y trasladado con él en sus viajes por el país. Pedro de Covilha, cautivo en el país del Preste Juan desde 1991, le contó a Francisco Alvares y los demás visitantes portugueses que

se podría comprar un mundo entero con él, porque de cuanto encerraba nunca sacaba algo, aunque era verdad que de las sedas y brocados sacaban muchas veces para dar a algunas iglesias y monasterios, como se había hecho tres años antes que llegásemos a la corte, que el Emperador había enviado gran cantidad de brocados y sedas de las dichas cuevas a Jerusalén, con un señor que se dice Abba Azerata, y que es capitán de la guardia de las hermanas del mesmo Emperador; cuando llevaban este presente, llevó también consigo 60 atabales que por todo el camino fuesen tañendo, y así pasó con ellos por el Cairo y allegó a Jerusalén y a la vuelta tornaron huyendo porque el Turco venía con gran poder entonces contra el Soldán de Egipto (fols. 167r-168r) ${ }^{47}$.

El presente testimonio enlaza con la creencia en la riqueza fabulosa del emperador de Etiopía, pero lo que ahora nos interesa es el reconocimiento de una tradición bien asentada de peregrinaciones etíopes a Jerusalén y de la costumbre de hacer valiosos regalos al Santo Sepulcro, un tipo de donación que parece ser tan habitual como lo era entre los reyes europeos ${ }^{48}$. Por otro lado, se nos habla del carácter festivo de la expedición religiosa, muy distinto del que se respiraba en las peregrinaciones europeas a Tierra Santa, de una devoción más interior. En efecto, Alvares llegó a Etiopía con su comitiva portuguesa en 1520. Si la peregrinación se produjo tres años antes, coincidió con la fecha de 1517 en que Selim I había culminado la invasión de los territorios del imperio mameluco y había entrado victorioso en El Cairo. Con ese regreso precipitado que menciona Alvares, se anunciaba no solo el fin del imperio mameluco sino también la interrupción de la tradición de peregrinar a Jerusalén que, como dice Alvares, debía de ser habitual:

Muchas veces solían ir d'estas tierras frailes y clérigos a Jerusalén en romería, y estando nosotros en Barua se juntó una cáfila ${ }^{49}$ de trescientos y treinta y seis frailes para ir allá, y entre ellos iban quince monjas. Esto sería por Navidad y

47 Cito en adelante solo los folios en la edición castellana de Francisco ÁLVAREZ citada en nota 36.

48 Son abundantes los testimonios que nos han dejado los peregrinos, en especial los referidos a los monarcas Carlos V, Felipe II y Felipe III. Francisco Guerrero, por ejemplo, refiere en su Viaje a feruasalén a finales del siglo XVI unos objetos sagrados que le muestran los franciscanos y que habían sido recién enviados por Felipe II.

49 Del término árabe qafilah. Según el DRAE, una cáfila es un «conjunto o multitud de gentes, animales o cosas, especialmente las que están en movimiento y van unas tras otras». 
luego, después de los Reyes, se pusieron en camino y caminaban poco a poco, de manera que vienen a llegar allá por la Semana Santa. La causa porque parten en aquel tiempo es porque entonces se acaba el invierno en Nobia [sic] a la entrada de Egipto, y por Egipto no llueve; y así caminando al fin del invierno hallan todavía agua por el camino si la han menester (fol. 168r).

Como vemos, por seguridad se viajaba en grupo y era el tiempo meteorológico el que marcaba la época en que se emprendía el viaje, previendo el momento de la llegada a Jerusalén en Semana Santa. El calor del desierto y la llegada del tiempo seco aconsejaban realizar la peregrinación en cuanto pasaba la Navidad. También en el occidente europeo se desaconsejaba hacer la peregrinación en solitario. Los europeos preferían el final de la primavera y el principio del verano para viajar desde Venecia -o desde cualquier otro puerto mediterráneo- hasta Tierra Santa. En Venecia las naves de los peregrinos zarpaban después de celebrar la Ascensión o la fiesta del Corpus en una solemne despedida, ya que el mar resultaba más peligroso en otoño o en invierno ${ }^{50}$.

El itinerario de esta peregrinación sigue el curso del Nilo. Al entrar en tierras de dominio musulmán, son mercaderes los que se comprometen a llevarlos sanos y salvos hasta El Cairo. Vemos, por tanto, cómo la coincidencia de intereses entre mercaderes y peregrinos facilitaba las peregrinaciones, fenómeno que también era frecuente en los puertos mediterráneos europeos ${ }^{51}$ :

Aquellos frailes, desque se vieron ajuntados de muchas partes allí en Barua, fueron entregados por el Visorrey Dori (que entonces era) a unos mahometas $[s i c]$ vecinos de Çuaquén, pueblo del Emperador a la raya de Egipto, y a otros de Rifa, que es otro pueblo en medio de Egipto junto al Nilo. Estos mahometas eran muy conoscidos mercaderes en las tierras del Emperador y ellos se obligaron a ponerlos en salvo dentro de la ciudad del Cairo (fol. 168r).

El concepto de peregrinación prolongada es muy diferente al europeo. Mientras estos suelen llegar a Venecia en solitario o en pequeños grupos y luego se embarcan en Venecia tras firmar un contrato con un patrón, los etíopes parten ya en grupo desde su tierra, prefieren cubrir etapas cortas, avanzan despacio lle-

50 En realidad, la tradición de interrumpir la navegación en el Mediterráneo durante el invierno era habitual ya entre los romanos.

51 Aunque lo habitual era dirigirse a Venecia al final del invierno para hacerse a la mar en primavera, ya en el siglo XVI no era extraño que muchos peregrinos europeos se dirigieran a Valencia, Barcelona, Marsella, Génova, Nápoles, etc., los puertos de los que partían las naves de los mercaderes hasta Alejandría o cualquier otro puerto del Mediterráneo Oriental. 
vando tiendas específicas para las celebraciones litúrgicas y concediendo mucho tiempo a la convivencia y la celebración religiosa:

Comenzaron su camino hasta Einacén, que estaba una jornada de Barua, y era en la señoría de Dafela y tenía muchos mantenimientos. Estas jornadas que ellos hacen son muy pequeñas porque, luego que son horas de vísperas, se paran y ponen sus tiendas de iglesias y dicen sus oficios divinos y la misa, en la cual comulgan todos. El día siguiente se parten a horas de tercia yendo todos cargados de sus mantenimientos y con sus calabazas y odres llenos de agua. Las tiendas de las iglesias van en camellos y las aras d'ellas llevan ellos con mucha reverencia, mudándose a ratos los que las llevan. Cada día podrían caminar dos leguas y yo me fui con ellos dos días, por ver el orden que tenían en el caminar. Del lugar de Einacén al de Çuaquén hay dos señorías o gobernaciones que se dicen Dafela y Canfela, y están sujetas al reyno de Bernagaes, y del un lugar al otro puede haber quince jornadas de cáfila de mercaderes, que es poco más de tres leguas por jornada. De Çuaquén a Rifa hay catorce jornadas de las mesmas, y todo aquello es ya tierra de Egipto muy poblada, sino en unas seis o siete leguas que, por falta de agua, dejan de estar pobladas. Por todo este camino hay muchos cristianos, que hacen limosna a los que van en romería y ellos están sujetos a mahometas. En el mesmo camino hay un monesterio, en el cual hizo vida San Antonio el primer monje de cuya orden son todos los monjes y frailes de la Etiopía. De Rifa al Cairo hay ocho días de camino, yendo siempre riberas del Nilo por tierras fertilísimas (fols. 168v-169r).

El relato de esta peregrinación, que se prometía feliz, da un giro total y nos muestra la cara más dramática de aventurarse por tierras lejanas en tiempos de turbulencias políticas. Veamos cómo refiere Alvares los hechos:

Estos frailes que ahora iban, desque pasaron de Çuaquén, dieron sobre ellos unos mahometas, que pudieron más que los que iban en su guarda y prendiéronlos matando los viejos y cativando los más mozos; y de trescientos y cuarenta y ocho, no escaparon sino quince y estos acabaron su peregrinaje. Yo vi después tres d'estos que me contaron sus trabajos, y me decían que aquel daño les fuera hecho, porque tenían amistad con nosotros; y cierto es así, que nosotros somos causa, porque ellos agora reciben mala vecindad de todos los mahometas. Desde Rifa al Cairo (como he dicho) es muy buena tierra y de gente blanca, y algunos d'ellos son mahometas, y otro judíos, y otros algunos cristianos. Cuando allegan estos romeros al Cairo, hacen estación en San Cosme y San Damián, y en Santa Bárbola [es decir, Santa Bárbara] y a una fuente que está en la huerta del Bálsamo ${ }^{52}$, y de allí a Jerusalén van en otros ocho días de

52 De esta huerta, donde descansó la Virgen en su huida a Egipto, hay numerosas noticias, pues todos los peregrinos que pasaban por El Cairo cuentan las virtudes del bálsamo que allí se extraía de una planta que no se criaba en ningún otro lugar y que producía un perfume que a los peregri- 
camino. Desde que aquestos frailes fueron presos, nunca han querido ir otros ningunos, ni clérigos tampoco en cáfila, si no son algunos que van disimulados como pasajeros. Los que van y vuelven a esta romería son tenidos por santos en todas partes (fol. 169r).

Eran frecuentes en Palestina y en Egipto los asaltos a peregrinos por parte de grupos de bandoleros (que habitualmente se les denominaba alárabes), a pesar de que los extranjeros iban siempre en grupo y acompañados por algún guía árabe. Lo menos malo es que estos grupos de jinetes, que solían aparecer por sorpresa, se conformasen con unas cuantas monedas, pero a veces el capricho de los asaltantes podía acabar con la vida del peregrino ${ }^{53}$. Está claro que los otomanos quisieron hacer ver a los etíopes y a portugueses las consecuencias funestas que les iban a ocasionar estas alianzas entre pueblos cristianos. Por eso «decían que aquel daño les fuera hecho, porque tenían amistad con nosotros» ${ }^{54}$.

Las consecuencias fueron tremendamente duras para los cristianos etíopes que vieron interrumpida así una tradición de siglos. Ese significado debemos dar a la frase «Desde que aquestos frailes fueron presos, nunca han querido ir otros ningunos, ni clérigos tampoco en cáfila, si no son algunos que van disimulados como pasajeros». En efecto, lo mismo que los españoles del siglo XVI, los peregrinos abisinios debían ocultar su identidad. Así, Francisco Guerrero declaró en 1588 al entrar en el Santo Sepulcro que su nombre era Alberto «porque pareciese más tudesco, y no español, que es cosa peligrosa que sepan que somos españoles, porque piensan que somos espías y nos toman por esclavos, y con hablar italiano nos los asseguramos d'esta sospecha» ${ }^{55}$, en 1595 el canario Ceverio de Vera pasó por italiano y en 1602 el catalán Miquel Matas por francés ${ }^{56}$.

nos cristianos les parecía milagroso. En realidad, era uno de los pocos lugares donde el peregrino podía comprobar que el milagro existía realmente, pues el perfume de aquel bálsamo era único y ya los sultanes mamelucos lo utilizaban para obsequiar con él a los príncipes amigos. Se recogen abundantes noticias de viajeros de cien años atrás en el libro de Víctor de LAMA DE LA CRUZ, Relatos de viajes por Egipto en la época de los Reyes Católicos, Madrid, 2013.

53 Se podrían mencionar muchos ejemplos de peregrinos extorsionados. Los franciscanos de la Custodia, por ejemplo, fueron encarcelados varios meses (muriendo algunos de ellos) cuando el sultán Selim I perdió unas naves combatiendo en el Mediterráneo contra los caballeros de San Juan.

54 Venganzas de este tipo, a modo de escarmiento, no eran extrañas en el comportamiento de los turcos. Baste recordar, por ejemplo, cómo en 1480 habían pasado a cuchillo a la población civil de Otranto y se podrían traer aquí numerosos ejemplos de actos de crueldad que buscaban minar la moral del adversario.

55 Francisco Guerrero, El viaje a ferusalem, ed. Julio AsENJo, p. 75.

56 Víctor de Lama De La CruZ, Urb Beata Hierusalem [ver n. 6], p. 20. 
Igualmente dramáticos fueron los siguientes años para la comunidad etíope de Jerusalén. Si durante el período mameluco los etíopes en Tierra Santa habían alcanzado su mayor prosperidad, en cuanto se produjo la conquista otomana de los lugares santos del cristianismo debieron emigrar en grupos hacia diversos países europeos. Cuando en 1522 Bartolomé de Salignac visitó Jerusalén, apenas quedaban etíopes en la ciudad ${ }^{57}$. Parece que en la década de 1530 empezaron a regresar y en la de 1560 la comunidad etíope ya había recuperado dos capillas del Santo Sepulcro ${ }^{58}$.

Mucho tiempo después, en 1706, Fray Matheo de Anguiano recordaría en la introducción de su Epitome historial y conquista espiritual del imperio Abyssino, en Etiopía la Alta que los etíopes «antiguamente solían peregrinar a Gerusalén, y ya lo han dexado, por los muchos intereses que les llevan los Turcos». De tal afirmación se desprende que el miedo y la prohibición de los primeros años de dominio otomano se transformó con el tiempo en un oneroso impuesto.

Por otro lado, Francisco Alvares se preocupó por conocer el mundo de las peregrinaciones abisinias y aún nos ofrece otros datos interesantes:

También hay otro camino de aquí a Jerusalem, que se puede ir en menos tiempo, y es de Macua ${ }^{59}$ al monte Sinaí por el mar Bermejo, que en quince días y en menos (según el tiempo) allegan allá; y del monte Sinaí a Jerusalén en ocho días ${ }^{60}$. Por este camino no se atreven a andar estos etíopes, porque no tienen navíos para ello, ni menos saben navegar, y así desean mucho que el rey de Portugal haga alguna fortaleza en Macua, para que de allí puedan ir más seguros en los navíos de los portugueses (fols. 169rv).

Esta segunda ruta pudo utilizarse en tiempo de paz y fuera de las fechas de la gran peregrinación, pero cuando se conoció su relación con los portugueses los cristianos etíopes seguramente tuvieron que renunciar a ella o encubrir su nacionalidad como hacían los españoles a finales del siglo XVI y principios del siglo XVII.

57 Enrico Cerulli, Etiopi in Palestina. Storia della Communità Etiópica de Gerusalemme, vol. 2, Roma, 1947, pp. 395-398; C.F. BECKINGHAM, Pantaleâo de Aveiro and the Ethiopian Community in ferusalem, en fournal of Semitic Studies, 7 (1962), p. 332.

58 Amnon COHEN y Bernard LEWIS, Population and Revenue in the Towns of Palestine in the Sixteenth Century, Princeton (New Jersey), 1978, p. 86 en nota.

59 La isla de Maqua está situada en el mar Rojo, cerca del estrecho de Bab-el-Mandeb. Desde allí se adentró la expedición de Francisco Álvarez en Etiopía.

60 Álvarez se muestra aquí un tanto optimista o quizá crédulo. Las etapas de las caravanas estaban bien establecidas, con los puntos de aprovisionamiento de agua y descanso. El viaje entre Jerusalén y el monte Sinaí que hizo, por ejemplo, Breidenbach con su comitiva duró quince días. Igualmente, en el viaje entre El Cairo y Jerusalén (el llamado camino de la Sagrada Familia) las caravanas de mercaderes solían emplear aproximadamente el mismo tiempo, dos semanas. 


\section{ALGUNAS CONCLUSIONES}

La interrupción violenta de esta peregrinación le impidió a Francisco Alvares referirnos todo lo relativo a la llegada y la estancia de los etíopes en Jerusalén. Sin embargo, hay suficientes datos para hacernos una idea muy aproximada de su desarrollo. Podemos estar seguros de que estas peregrinaciones fueron habituales hasta 1517. Sin contar con los testimonios concretos que se podrían espigar de otras fuentes anteriores, esto es lo que se desprende de la tradición de peregrinar a Jerusalén en la misma época del año, de que se siguieran por lo general unos itinerarios previamente fijados y de que se pusieran habitualmente en manos de mercaderes egipcios para que les condujesen hasta El Cairo. En este caso se mencionan dos itinerarios: el que descendía junto al Nilo y el marítimo del mar Rojo. Cada uno presentaba sus ventajas y sus inconvenientes, y seguramente se elegía en función de las circunstancias del peregrino y la época del año. El primero parece ser el habitual para realizar en grupo; el marítimo probablemente lo prefería quien peregrinara en solitario pagando un pasaje al patrón de una embarcación que lo dejara cerca del Sinaí, para seguir luego el último trecho en una caravana.

De la misma manera que los reyes y príncipes cristianos, los mandatarios etíopes demuestran su generosidad y sus convicciones religiosas haciendo obsequios excepcionales a la Iglesia. En este caso son bordados y sedas lo que el Emperador envía como presente a la iglesia del Santo Sepulcro.

Entre los peregrinos predominan los clérigos y monjas, en mayor medida que en las peregrinaciones españolas y europeas, en que también eran frecuentes los religiosos de distinta categoría.

Eran estas expediciones muy numerosas, aunque no tanto como las musulmanas, y podían tener un carácter festivo, como sugieren esos sesenta atabales resonando en el camino y especialmente en El Cairo. Parece que se viajaba a pie y que se demoraban varios meses -de Navidad a Semana Santa- por la impedimenta que llevaban. No recorrían más de dos o tres leguas al día y los coptos egipcios solían recibirles como a hermanos apoyándoles con limosnas.

Estaban sujetas, como las peregrinaciones occidentales, a los peligros derivados de las tensiones políticas. No era extraño que en cada expedición perdiera la vida algún peregrino por las más diversas razones (tormentas, enfermedades, asaltos, pendencias...). Hay que reconocer, no obstante, que en las peregrinaciones occidentales no se conoce una masacre como la que nos refiere el cronista portugués. Las circunstancias en que se desarrollan las dos peregrinaciones reseñadas revelan cómo la alianza entre los etíopes y portugueses tuvo consecuencias trágicas para los peregrinos etíopes y las peregrinaciones a Jerusalén debieron 
interrumpirse o reducirse por un tiempo considerable difícil ahora de precisar, ya que el motivo que alega Anghiano en 1706 son los altos impuestos que se les pretende cobrar.

En resumen, Francisco Alvares y sus traductores ofrecieron al público europeo del siglo XVI un testimonio revelador de las costumbres religiosas de un pueblo cristiano tan alejado y aislado como el etíope. Esta información acrecentaba los conocimientos y las experiencias de unos lectores que veían día a día cómo se ensanchaba ante sus ojos el mundo conocido y cómo su vida particular se empequeñecía ante vivencias tan distintas a las de España y Portugal, en unos años en que se había efectuado ya el cisma protestante, se estaba desarrollando el Concilio de Trento y la Inquisición vigilaba con lupa sus conductas religiosas.

\section{REFERENCIAS BIBLIOGRÁFICAS}

Almagià, Roberto, Contributi alla storia della conoscenza dell'Etiopia, Padova, 1941.

Alvares, Francisco, Verdadera Informaçam das Terras do Preste foao das Indias, Lisboa, 1540.

ÁlvareZ, Francisco, Historia de las cosas de Etiopía, trad. de fray Tomás de Padilla, Anvers, 1557.

ANGUIANO, Fray Matheo de, Epitome historial y conquista espiritual del imperio Abyssino, en Etiopía la Alta, o sobre Egypto, a cuyo emperador suelen llamar Preste fuan los de Europa, Madrid, 1706.

ARANDA, Antonio de, Verdadera información de la Tierra Santa, Alcalá de Henares, 1563.

BALDRIDGE, Cates, Prisoners of Prester Fohn: The Portuguese Mission to Ethiopia in Search of the Mytical King, 1520-1526, Jefferson (North Carolina), 2012.

Beckingham, C.F., Pantaleâo de Aveiro and the Ethiopian Community in Ferusalem, en Fournal of Semitic Studies, 7 (1962), pp. 325-338.

BeshaH, Giron y Morid Wolde AREgaY, The Question of the Union of the Churches in Luso-Ethiopian Relations (1500-1632), Lisboa, 1964.

Breidenbach, Bernardo de, Viaje de la Tierra Santa, Martín MARTínez de Ampiés (ed.), Zaragoza, 1498.

Cartas de Affonso de Albuquerque, seguidas de documentos que as elucidam, t. I, Lisboa, 1984 (1 de diciembre de 1513 desde Cananor. Carta al rey sobre la detención de peregrinos abisinios).

CERONE, Francesco, La politica orientale di Alfonso di Aragona, Napoli, 1903.

CERULl, Enrico, Eugenio IV e gli Etiopi al Concilio di Firenze nel 1441, Roma, 1933.

Cerulli, Enrico, Etiopi in Palestina. Storia della Communità Etiópica de Gerusalemme, 2 vols., Roma, 1943 y 1947. 
COHEn, Amnon y Bernard LEWIS, Population and Revenue in the Towns of Palestine in the Sixteenth Century, Princeton (New Jersey), 1978.

DONZEL, Emery van, The Ethiopian Presence in Ferusalem until 1517, en The Third International Conference on Bilad al-Sham (Palestine 19-24 April 1980), vol. 1, JerusalemAmman, 1983, pp. 93-104.

DONZEL, Emery van, Were there Ethiopians in ferusalem at the time of Saladin's Conquest in 1187?, en Krijna Nelly CiggaAR y Herman G.B. Teule (eds.), East and West in the Crusader States II, Leuven, 1999.

Elli, Alberto, Storia de la Chiesa Ortodossa Tawahedo d'Etiopia, 2 vols., Milano, 2017.

EsCobar CABEZA DE VACA, Pedro, Luzero de la Tierra Sancta, Valladolid, 1587.

GalÉ, Enrique, ed., Pedro Manuel de Urrea, Peregrinación de las tres casas sanctas de Zherusalem, Roma y Santiago, 2 vols., Zaragoza, 2008.

GRABOÏs, Aryeh, Le pèlerin occidental en Terre Sainte au moyen âge, Paris/Bruxelles, 1998.

GUERrERO, Francisco, El viaje a ferusalem, ed. por Julio ASENJO. Disponible en https:// www.uma.es/victoria/guerrero/Francisco_Guerrero_-_Viaje_de_Jerusalem.pdf

HofmanN, Georg. (ed.), Epistolae pontificiae ad concilium Florentinum spectantes, vol. 2, Rome, 1944.

IsAAC, Ephraim, A New Text-Critical Introduction to «Maṣhafa Berhān», Leiden, 1973.

KaPlan, Steven, Ezana's Conversión Reconsidered, en Fournal of Religion in Africa, 13-2 (1982), pp. 101-109.

KELLY, Samantha, Ewostateans at the Council of Florence (1441): Diplomatic Implications between Ethiopia, Europe, Jerusalem and Cairo, en Afriques [Mis en ligne le 29 juin 2016: https://journals.openedition.org/afriques/1858]

KozlowsKa, Marta, First Contacts between Ethiopia and Europe (from de Fourteenth until Beginning of the Sixteenth Century), en Studies of the Department of African Languages and Cultures, vol. 37, 2006, pp. 5-46.

LAMA DE LA CRUZ, Víctor de, Relatos de viajes por Egipto en la época de los Reyes Católicos, Madrid, 2013.

LAMA DE La CRUZ, Víctor de, El vallisoletano Pedro Escobar Cabeza de Vaca en su «Luzero de la Tierra Sancta», en Castilla. Estudios de Literatura, 6 (2015), pp. 367-401.

LAMA DE LA CRUZ, Víctor de, URBS BEATA HIERUSALEM. Los viajes a Tierra Santa en los Siglos XVI y XVII. Catálogo de la exposición en la BNE del 22-09-2017 al 8-01-2018, Madrid, 2017.

LAMA DE LA CRUZ, Víctor de, Los viajes a Tierra Santa en los Siglos de Oro: entidad y fortuna de un género olvidado, en Revista de Filología Española, 99-1 (enero-junio 2019), pp. 89-112.

MARINESCU, Constantin, La politique orientale d'Alfonse V d'Aragon, roy de Naples (14161458), Barcelona, 1994. Disponible en https://books.google.es/books?id=9IPtrh4L $\mathrm{bXQC} \&$ printsec $=$ copyright $\&$ redir_esc $=\mathrm{y} \# \mathrm{v}=$ onepage $\& \mathrm{q} \& \mathrm{f}=$ true

MOLL, Jaime, Amberes y el mundo hispánico del libro, en Werner THOMAS y Robert A. VERDONK (eds.), en Encuentros en Flandes: relaciones e intercambios hispanoflamencos a inicios de la Edad Moderna, Leuven, 2000, pp. 117-131. 
O'Mahony, Anthony, Between Islam and Christendom: the Ethiopian Community in ferusalem before 1517, en Medieval Encounters, vol. 2-2 (1996), pp. 140-154.

RAMUSIO, Giovanni Battista, Primo volumen delle navigationi et viaggi, Venecia, 1550.

RiCHARD, Jean, La papauté et les Missions d'Orient au Moyen Âge (13-e $15^{e}$ siècles), Rome, 1977.

RICHARD, Jean, Les récits de voyages et de pèlerinages, Turnhout, 1981.

RodrígueZ MoÑIno, Antonio (ed), Diego de Mérida, Viaje a Oriente, en Analecta Sacra Tarraconensia, 18 (1945), pp. 11-187.

Salvadore, Matteo, The African Prester Fohn and the Birth of Ethiopian-European Relations, 1402-1555, London-New York, 2017.

Stoffregen-Pedersen, Kirsten, The Qeddusan: The Ethiopian Christians in the Holy Land, en Anthony O'MAHONY, Göran GUNNER y Kevork HinTLIAN (eds.), The Christian Heritage in the Holy Land, London, 1995, pp. 129-148.

TAMrat, Taddesse, Church and state in Ethiopia, 1270-1527, Oxford, 1972. 